\title{
Information model of the construction process in space and time
}

\author{
Vadim Kabanov* \\ Moscow State University of Civil Engineering, 129377, Moscow, Russia
}

\begin{abstract}
BIM 3D technologies are traditionally used in the design of construction projects. The prospect of turning BIM 3D into BIM 5D is associated with the need to build information models of the construction process that are able to accurately determine the coordinates of construction and installation work at any time. The purpose of this work is to build an information model in space and time. The paper substantiates the sources of initial quantitative information. A BIM 3D model of a object of construction is a source of information for determining the coordinates (position in space) of the construction process. To calculate the speed of construction, it is proposed to use information about construction resources using national codes. A mathematical apparatus is proposed that can integrate the construction speed value into coordinates using BIM 3D technologies. A flowchart for software product development is proposed. The information model of the building process in space is represented as a vector. The coordinates of the beginning of a vector can always be represented as: $X=0, Y=0, Z=0$, and the coordinates of the end of this vector are: X, Y, Z. Moving along the vector is described depending on the speed of build.
\end{abstract}

\section{Introduction}

A digital model of a construction object at the design stage is commonly referred to as a $3 \mathrm{G}$ model built in a BIM environment. The information model describing the functioning of construction processes is called the $5 \mathrm{G}$ BIM model [1]. It is important to note that the information model of the construction process describes the sequence of creating structures of buildings and structures [2,3], as well as the interaction of all construction participants [4], including state supervision bodies [5]. Such a variety of ideas about the information model of construction leads to the need to clarify the concept of "information model of the construction process". In this paper, the "information model of the construction process" is the process of constructing structures of buildings and structures in the space provided by the project ( $3 \mathrm{G} \mathrm{BIM}$ ) and in time, which is determined by the construction schedule of the capital construction object. When building an information model, an important component is feedback, which is information obtained as a result of the use of modern surveillance tools, which is commonly called additional reality [6].

* Corresponding author: kabanovvn@yandex.ru 
The published research results can be used in solving problems that are necessary for building an information model of the construction process. These General solutions include:

- building a model structure that can provide interaction of source data, including existing databases for information modeling in 3G BIM [7], as well as a mathematical apparatus for calculating the quantitative values of the result (output values) [8];

- application of logical and mathematical functions that describe the relationship between the technological operations of the construction process and the organizational structure of the construction of a capital construction object [9], including by integrating such functions into existing BIM models [10];

- allocation of planning units [11] taking into account the potential of the technological process of construction and installation works [12].

It should be emphasized that work on building an information model of a separate construction process is not uncommon. However, the published results consider important, but rather narrow problems of information modeling of the process of construction of specific building structures. For example:

- building an information model for the construction process that is performed manually [13];

- modeling of the process from the moment of its production of a construction structure at a construction industry enterprise to the moment of its installation in the design position at a capital construction facility [14];

- research of problems of "computer vision" in the construction of building structures [15];

- application of BIM technologies in the organization of quality control of concrete production [16].

It is necessary to note the interest aroused by the issues of information modeling of material support processes in the construction of buildings and structures $[17,18]$. At the same time, the authors focus on economic efficiency, including in "lean construction" [19], as well as due to the productivity of management personnel when using BIM technologies [20]. This publication intentionally does not provide a mathematical tool that can be used to calculate economic indicators that are used to describe performance. The author of the publication considers quantitative indicators describing the processes of construction and installation works with reference to space and time.

When studying the published research results, the author failed to find any concrete proposals for describing the process of functioning of a individual construction process in space and time. To fill this gap, real work has been done. The purpose of the research: to develop an information model of the construction process that describes the process of construction and installation works in space and time. To achieve this goal, the following tasks have been completed:

- identified sources of information for building the model;

- a mathematical apparatus has been developed that describes the movement of the construction process along known coordinates in space in each unit of time;

- a flowchart of a software product has been developed that can be integrated into existing 3D BIM technologies.

\section{Method of research}

The study of the processes of building an information model of the construction process was carried out on the basis of procedures that are provided for by current international standards, as well as regulatory documents of the Russian Federation. To form the structure 
of information that describes construction objects, as well as construction processes functioning, the methods that are given in ISO 12006-2:2015 "System of standards for information modeling of buildings and structures were used. Building construction. Organization of information about construction works. Part 2. Basis for classification". The development of an information system for describing construction processes in space and time was carried out in accordance with the procedures established by ISO 22263-2017 "Model for building the work of a data organization. Structure of project information management". The construction of the exchange mechanism between the initial quantitative values and the results obtained using mathematical calculations was regulated by the procedure established by ISO 12006-3: 2007 "System of standards for information modeling of buildings and structures. Building construction. Organization of information about construction works. Part 3. Framework for object-oriented information".

The development of an information model of the construction process in relation to the conditions of the Russian Federation provided for the following requirements:

- when designing construction processes using information models, the requirements of BR (body of rules) 404.1325800.2018 "Building information modeling were taken into account. Project planning guide";

- when modeling the production process of construction - BR (body of rules) 333.1325800.2017 "Information modeling of buildings. Modeling recommendations for various stages of the project lifecycle";

- requirements for components of the information model of the construction process were adopted in accordance with BR (body of rules) 328.1325800.2017 "Building information modeling. Components. Guidelines and requirements";

- the exchange rules between the quantitative values that make up the initial information and the calculated values of the result, which describes the position of the construction process in space and time, were established taking into account the requirements of BR (body of rules) 331.1325800.2017 "Building information modeling. Modeling recommendations and requirements for data exchange between building information models and application package models".

The construction of a graphical representation of the information model of the construction process in space and time was performed in compliance with the norms set out in the в ISO 5807:1985 "Information processing - Documentation symbols and conventions for data, program and system flowcharts, program network charts and system resources charts (in the version 2019)".

\section{Results}

Information about the construction process can be stationary or dynamic. Stationary character is information describing the readiness to function of the construction process. This information is documented, for example, in the form of an act and describes the fulfillment of the conditions necessary to start the relevant construction and installation work. A description of the conditions required to start work is usually provided in the relevant national technical and technological regulations. The most common types of such information are:

- results of geodetic measurements (working and design marks made in nature);

- characteristics of surfaces of structures of buildings and structures;

- technical requirements for the installation of main and auxiliary technological equipment, as well as for its safe operation;

- input control system designed for structures, materials and semi-finished products entering the construction site and used in the production of works; 
- technological equipment, manual electric tools, measuring instruments designed for quality control.

The initial data required to describe indicators that are stationary is generated by digitizing existing technical regulations and standards in construction. It is important to emphasize that the conversion to digital format should be accompanied by binding to the classification code of construction resources and technologies [21, 22]. In the Russian Federation, technology classification codes are the table number in the state element building codes. It is important to emphasize that the current estimated standards are posted on the official website of the Ministry of construction of Russia (minstroyrf.gov.ru). Official information is provided in text format. Converting to digital format will require significant, but one-time labor costs.

It is advisable to build an information model of the building process by analogy with the construction of a classical database. The Central place in the description of each technological process is the value of the speed of movement of the technological process on the construction object. The speed of technology movement refers to a dynamic indicator and shows the amount of work performed per unit of time. It is not difficult to record the movement of a technological process in time as an inequality:

$$
0<v_{t} n t_{n}<V
$$

where $v_{t}$ - is the speed (intensity) of work production, measured by the volume of work $\left(V_{t}\right)$ produced per unit of time $\left(t_{n}\right)$;

- $t_{n}$ - set unit of time (for example, hour, shift, day);

- $n$ - the number of units of time $\mathrm{t}$ that has passed since the start of construction and installation work, measured in units.

When determining the quantitative value of the intensity (speed)of construction and installation work, it is useful to divide all construction processes by the degree of mechanization of work. This division involves the formation of 3 groups. The first group includes fully mechanized processes, for example, the production of earthworks for the construction of a pit. For this category of construction processes, the share of manual labor is negligible, which allows, in most cases, to neglect this value. The speed of work for fully mechanized construction processes is equal to the operational productivity of the construction equipment used. The second group combines processes that cannot be performed without the use of construction machines, such as the installation of precast concrete elements or the laying of concrete mix in the formwork. For construction processes in this group, it is important to compare the operational performance of construction equipment and the total productivity of the set number of workers when calculating the speed of work. The intensity (speed) of work is usually assumed to be equal to the minimum of the compared values. The third group consists of processes performed manually or with such a proportion of mechanization that can be neglected (mechanization in this case is the supply of building materials to the work area or workplace), for example, the construction of walls made of small-piece materials (bricks or concrete blocks) or the device of partitions made of drywall. For manual construction processes, the work intensity is the sum of the workers productivity.

The speed of construction and installation work $\left(v_{t}\right)$ characterizes the movement of construction processes over time. For each of the above groups of construction processes, the calculation of the construction speed can be calculated using the following formulas:

- for a fully mechanized process:

$$
v_{t}=W
$$


where $W$-is the installed operating capacity of the construction machine, measured in units of volume $(V)$ per unit of time $(t)$;

- for the construction process involving construction machines and construction workers:

$$
W-\frac{N}{R}=\left\{\begin{array}{l}
>0 \Rightarrow v_{t}=\frac{N}{R} \\
<0 \Rightarrow v_{t}=W
\end{array}\right.
$$

where $N$ - Is the number of construction workers performing the work required by the construction process, measured in the number of people;

- $R$ - the labor costs required to perform a unit volume of work are measured in manhours required to perform a unit volume of work;

- for a construction process that is performed manually:

$$
v_{t}=R
$$

Building structures most often have the form of a rectangular parallelepiped. The process of constructing structures of this type is the movement of workers on a site that has the shape of a building structure (a rectangular parallelepiped), which can be described by a cloud of points [23]. The movement of workers and construction machines can be represented as movement along a rectangular parallelepiped. For information about spatial changes, it is advisable to use standard measurements in the coordinate system $X, Y, Z$. In this case, the speed of work can be represented as a unit vector, which is the diagonal of a rectangular parallelepiped and is equal to the specified volume of work $V$ :

$$
|\vec{V}|=\sqrt{X_{V}^{2}+Y_{V}^{2}+Z_{V}^{2}}
$$

where $V-$ is the volume of the structure (a structure in the form of a rectangular parallelepiped, $|\vec{V}|=V$ ), which is built using the construction process, measured in units of volume;

- $X_{V}, Y_{V}, Z_{V},-$ corresponding coordinates of the end of the diagonal (vector) of a rectangular parallelepiped, provided that the beginning is at the point $X_{0}=Y_{0}=Z_{0}=0$;

The information model of the construction process can describe the construction of structures in space and time. To describe changes in time it is sufficient to Express the time from the inequality 1 :

$$
n t=\frac{V}{v_{t}}
$$

where $V$ - is the volume of work (the volume of a rectangular parallelepiped) set by the architectural and structural solutions of the construction object, measured in units of volume;

$-v_{t}$ - the speed of construction or the amount of work performed per unit of time " $t$ ", calculated using formulas 2-4, depending on the construction processes used, measured in units of volume per unit of time;

$-t$ - the unit of time used in calculations, measured in units of time;

- $n$ - the number of time units " $t$ " that is needed to complete the scope of work $V$ when construction the structure, the volume $V$ measured in units of volume. 
For descriptions of the movement of building process in space it is advisable to apply a mathematical description of the motion of a point on the by vector with coordinates: $X_{0}=Y_{0}$ $=Z_{0}=0$ if the end of the vector matches is the diagonal of a rectangular parallelepiped at the point $X_{V}, Y_{V}, Z_{V}$. This description is most simply presented using trigonometric functions that describe the angles of inclination of the vector $\vec{V}$ projections on the corresponding planes of the Cartesian coordinate system. If the construction process moves along a vector $\vec{V}$ whose start coordinates are described as $X_{0}=Y_{0}=Z_{0}=0$, and the end coordinates take the value $X_{V}, Y_{V}, Z_{V}$, then the increment $\Delta X_{n}$ on the value $n v_{t}$ along the vector will be described:

- on the $X$-axis:

$$
\Delta X_{n}=n v_{t} \sin (X Z) \text { or } \Delta X_{n}=n v_{t} \sin (X Y)
$$

where $\Delta X_{n}-$ is the increment on the $X$-axis corresponding to the amount of work performed in the amount of $n v_{t}$;

- $n$ - number of time units since the start of construction and installation works;

- $v_{t}$ - the amount of work performed per unit of time " $t$ ";

- $\sin (X Z)$ describes the position of the vector $\vec{V}$ projection on the $X O Z$ plane, $\sin (X Z)=\frac{Z}{\sqrt{X^{2}+Z^{2}}}, \sin (X Y)$ describes the position of the vector projection on the $X O Y$ plane, $\sin (X Y)=\frac{Y}{\sqrt{X^{2}+Y^{2}}}$;

- on the $Y$ axis:

$$
\Delta Y_{n}=n v_{t} \sin (Y Z) \text { or } \Delta Y_{n}=n v_{t} \sin (X Y)
$$

where $\Delta Y_{n}$ - is the increment on the $Y$-axis corresponding to the amount of work performed in the amount of $n v_{t}$;

- $\sin (Y Z)$ describes the position of the vector $\vec{V}$ projection on the $Y O Z$ plane, $\sin (Y Z)=\frac{Z}{\sqrt{Y^{2}+Z^{2}}}, \sin (X Y)$ describes the position of the vector projection on the $X O Y$ plane, $\sin (X Y)=\frac{X}{\sqrt{X^{2}+Y^{2}}}$;

- on the $Z$ axis:

$$
\Delta Z_{n}=n v_{t} \sin (X Z) \text { or } \Delta Z_{n}=n v_{t} \sin (Y Z)
$$

where $\Delta Z_{n}-$ is the increment along the $Z$-axis of the corresponding amount of work performed in the amount of $n v_{t}$; 


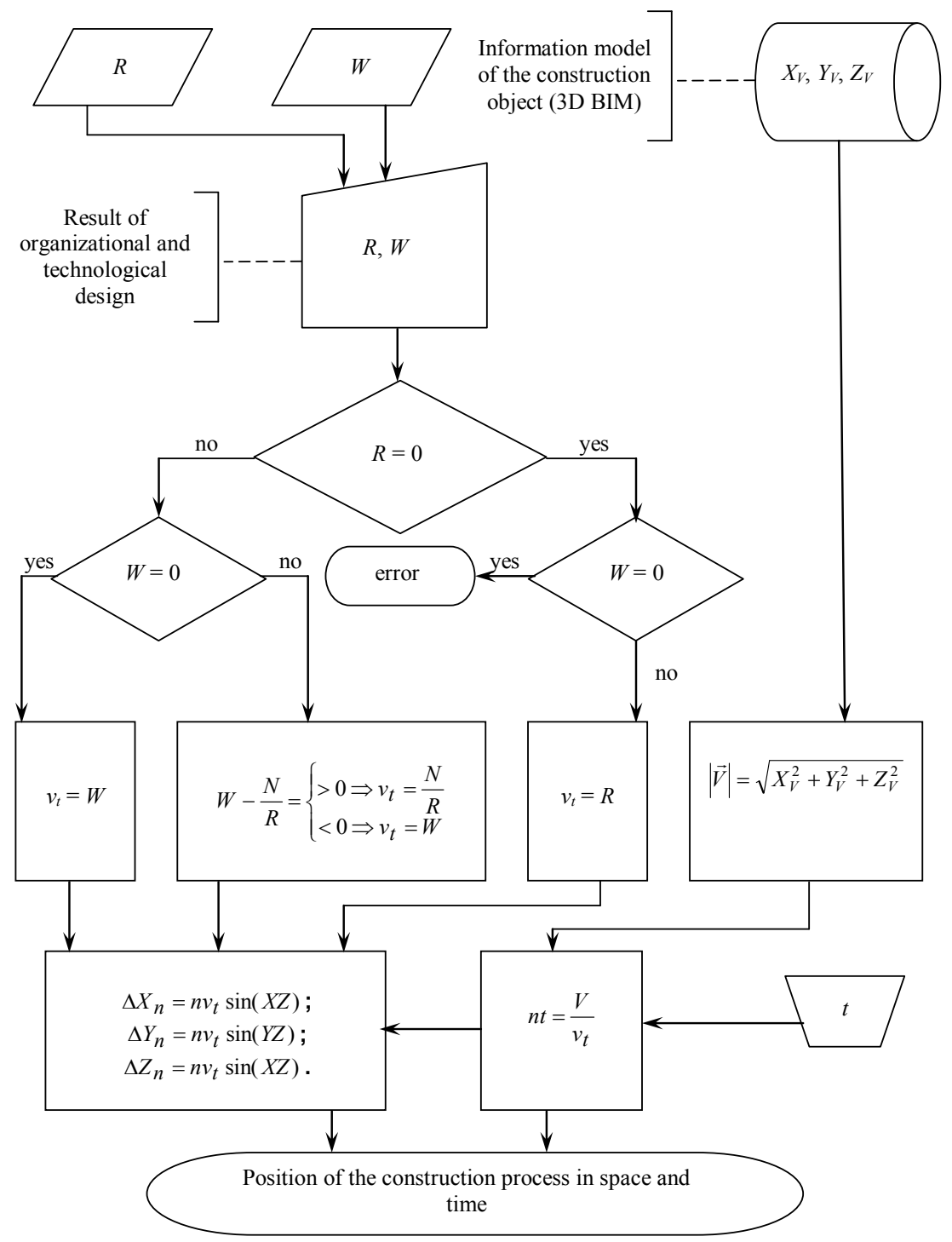

Fig. 1. Flowchart for determining the position of the construction process in space and time.

Built by the author according to the rules ISO 5807:1985

- $\sin (X Z)$ describes the position of the vector $\vec{V}$ projection on the $X O Z$ plane, $\sin (X Z)=\frac{X}{\sqrt{X^{2}+Z^{2}}}, \sin (Y Z)$ describes the position of the vector projection on the $Y O Z$ plane, $\sin (Y Z)=\frac{Y}{\sqrt{Z^{2}+Y^{2}}}$.

The given sequence of forming an information model of the construction process in space and time is shown in Fig. 1. 


\section{Conclusions}

These research results allow us to formulate the following conclusions:

1.to build an information model of the construction process with reference to spatial coordinates and time from the beginning to the end of the work, there is reliable source information. The basic information for describing changes in construction is the existing regulatory framework in the Russian Federation in construction, which determines the speed of construction depending on the number of attracted labor resources and means of mechanization. The initial information that describes the construction object in 3D BIM is the architectural and construction of the project. Representation of architectural planning and design solutions in existing software products makes it possible to find the coordinates of the beginning and end of the vector describing the scope of work for each type of construction process.

2. for information modeling of the construction process in time, it is necessary and sufficient to establish the degree of mechanization of the construction process (determine whether it belongs to one of the 3 groups). The ratio of the volume of work to productivity provides a value for the duration of construction (the number of individual time intervals).

3. Spatial modeling of the construction process should be represented as a vector, which is a diagonal of a rectangular parallelepiped. In this case, the movement of the construction process in space is described by elementary trigonometric equations.

4. Building an information model of the construction process in space and time significantly reduces labor costs when building construction schedules for objects as a whole. Allows you to simulate the simultaneous operation of several construction processes. Provides the choice of organizational and technological solutions that most fully utilize the potential of labor resources and means of mechanization.

\section{References}

1. A.V. Ginzburg, Building life cycle information modeling, Industrial and civil construction 9, 61-65 (2016)

2. P.B. Kagan, S.V. Komissarov, Improving methods of flow chart formation in construction, Online Bulletin of VolgGASU 3, 17 (2013)

3. V.V. Talapov, About the general scheme of the information model of construction object, News of higher educational institutions 1, 91-97 (2017)

4. B.V. Budzulyak, N.F. Seleznev, L.P. Moiseyev, and A.B. Ganbarov, Innovative approaches to construction system quality control organization: from the technical project up to the project realization, Pipeline transport: theory and practice 6, 40-44 (2013)

5. D.V. Topchy, A.Y. Tokarsky, Improving the management of construction and installation work through the use of information models in the implementation of oversight procedures Building production 2, 0-35 (2019)

6. R.L. Machado, C. Vilela Conceptual framework for integrating BIM and augmented reality in construction management, Journal of civil engineering and management 26(1) 83-94 (2020) doi: 10.3846/jcem.2020.11803

7. A. Naneva, M. Bonanomi, A. Hollberg, Habert, G. and D. Hall Integrated BIM-Based LCA for the Entire Building Process Using an Existing Structure for Cost Estimation in the Swiss Context, Sustainability 12(9), (2020) doi: 10.3390/su12093748 
8. O. N. Kuzina, Formation of the "executive" information model at the construction stage (C-BIM), Science and business: ways to develop 7, 43-47 (2019)

9. A.A. Morozenko, D.V. Krasovskiy, Logic mathematical function of forming the communications in the organizational structure of the project based on the matrix of key events, Scientific and technical bulletin of the Volga region 6, 57-59 (2018)

10. C.P. Schimanski, Pasetti Monizza G., C. Marcher and D.T. Matt, Development of a BIM-based production planning and control system for Lean Construction through advancement and integration of existing management techniques, Frontiers of engineering management, (2020) doi: 10.1007/s42524-020-0105-5

11. Ya.V. Zharov, Organizational technological design in construction based on an intelligent planning unit, Bulletin of civil engineers 6, 193-199 (2019)

12. A.A. Lapidus, A.N. Markov, Model of production potential of roof structures of residential multi-storey buildings, Prospects for the development of the construction complex 1, 86-94 (2015)

13 M.F. Kuzhin, S.S. Safronov, Information modeling in the organization of construction production, System technology 4, $72-77$ (2018)

14. Y. Al-Saeed, D.J. Edwards, S. Scaysbrook, Automating construction manufacturing procedures using BIM digital objects (BDOs) Case study of knowledge transfer partnership project in UK, Construction innovation England, (2020) doi: 10.1108/CI12-2019-0141

15. H. Deng, H. Hong, D.H. Luo, Y.C. Deng and C. Su, Automatic Indoor Construction Process Monitoring for Tiles Based on BIM and Computer Vision, Journal of construction engineering and management 146(1) (2020) doi: 10.1061/(ASCE)CO.1943-7862.0001744

16. M. Hamooni, M. Maghrebi, J.M. Sardroud, and S. Kim, Extending BIM Interoperability for Real-Time Concrete Formwork Process Monitoring, Applied sciences-basel 10(3), (2020) doi: 10.3390/app10031085

17. T. Moses, D. Heesom, D. Oloke, Implementing 5D BIM on construction projects: contractor perspectives from the UK construction sector, Journal of engineering design technology, (2020) doi: 10.1108/JEDT-01-2020-0007

18. Q. Chen, B.T. Adey, C. Haas and D.M. Hall, Using look-ahead plans to improve material flow processes on construction projects when using BIM and RFID technologies, Construction innovation England (2020) doi: 10.1108/CI-11-2019-0133

19. M.D. Andujar-Montoya, A. Galiano-Garrigos, V. Echarri-Iribarren and C. RizoMaestre, BIM-LEAN as a Methodology to Save Execution Costs in Building Construction-An Experience under the Spanish Framework, Applied scenes-basel 10(6), 2020 doi: 10.3390/app10061913

20. P. Mesaros, T. Mandicak, A. Behunova Use of BIM technology and impact on productivity in construction project management, Wireless networks, (2020) doi: 10.1007/s11276-020-02302-6

21. I.D. Titova, V.A. Volkodav, The history and development of the classification system for the construction industry, Construction of unique buildings and structures 1, 20-29 (2020)

22. K.V. Gorlov, B.V. Zhadanovsky, V.N. Kabanov, Catalog of progressive technological processes of the main types of construction and installation works (Moscow Institute of Gosstroy of the USSR, 1990) 
23. Se Kim, Sa Kim, D.E. Lee, Sustainable Application of Hybrid Point Cloud and BIM, Method for Tracking Construction Progress Sustainability 12(10), (2020) doi: $10.3390 /$ su12104106 